\title{
PREGNANCY EXPERIENCE OF MOTHERS WITH HUMAN IMMUNODEFICIENCY VIRUS INFECTION
}

\author{
Lellyawaty, Dhesi Ari Astuti, Yekti Satriyandari \\ Universitas ‘Aisyiyah Yogyakarta
}

\begin{abstract}
Background: UNAIDS data showed that in 2018, worldwide 36.9 million people were living with human immunodeficiency virus (HIV). There were 4,400 cases occurred among adults (over 15 years old), nearly $43 \%$ of them were women. Approximately $24 \%$ of deaths in pregnant or postnatal women in Sub-Saharan Africa are related to HIV infection. Pregnancy and postpartum are a time of persistent HIV risk and have a greater risk of death. Therefore, special attention is needed for pregnant women with HIV. This study aimed to investigate the pregnancy experience of mothers with HIV.

Subjects and Method: This was a systematic review using articles from PubMed and Proquest. The articles were selected from qualitative studies published from 2015 to 2018. The keywords used in this study were "pregnant HIV" OR "pregnancy HIV" AND experience*. The data were analyzed using Population, Exposure, Outcome, and Study (PEOS) design framework, PRISMA flow diagram, data extraction, the Critical Appraisals Skills Programme (CASP), and mapping of findings.

Results: Seven articles were obtained from 378 selected articles. These studies reported that the hidden HIV status was due to lack of courage, violence, and stigma from the community. The lack of support from health workers in providing pregnancy information and care about HIV reduced anti-retrovirus therapy (ART) adherence. Support from family and peers prevented HIV transmission to infant. Pregnant mothers with HIV positive hoped that their pregnancy will be safe and healthy, and their babies would be free of HIV.

Conclusion: Hidden HIV status among pregnant women remains a concern. Positive support from peers, community, and health workers, are needed to motivate pregnant women with HIV to improve their health.
\end{abstract}

Keywords: HIV, pregnancy, experience, stigma, ART

\section{Correspondence:}

Lellyawaty. Universitas 'Aisyiyah Yogyakarta. Jl. Siliwangi (West Ringroad) No. 63 Mlangi Nogotirto, Gamping, Sleman, Yogyakarta. Email: lellyawaty3o@gmail.com Mobile: 081268025172. 